Historic, Archive Document

Do not assume content reflects current scientific knowledge, policies, or practices. 



\section{WASPS WAGE WAR ON ALFALFA WEEVILS}

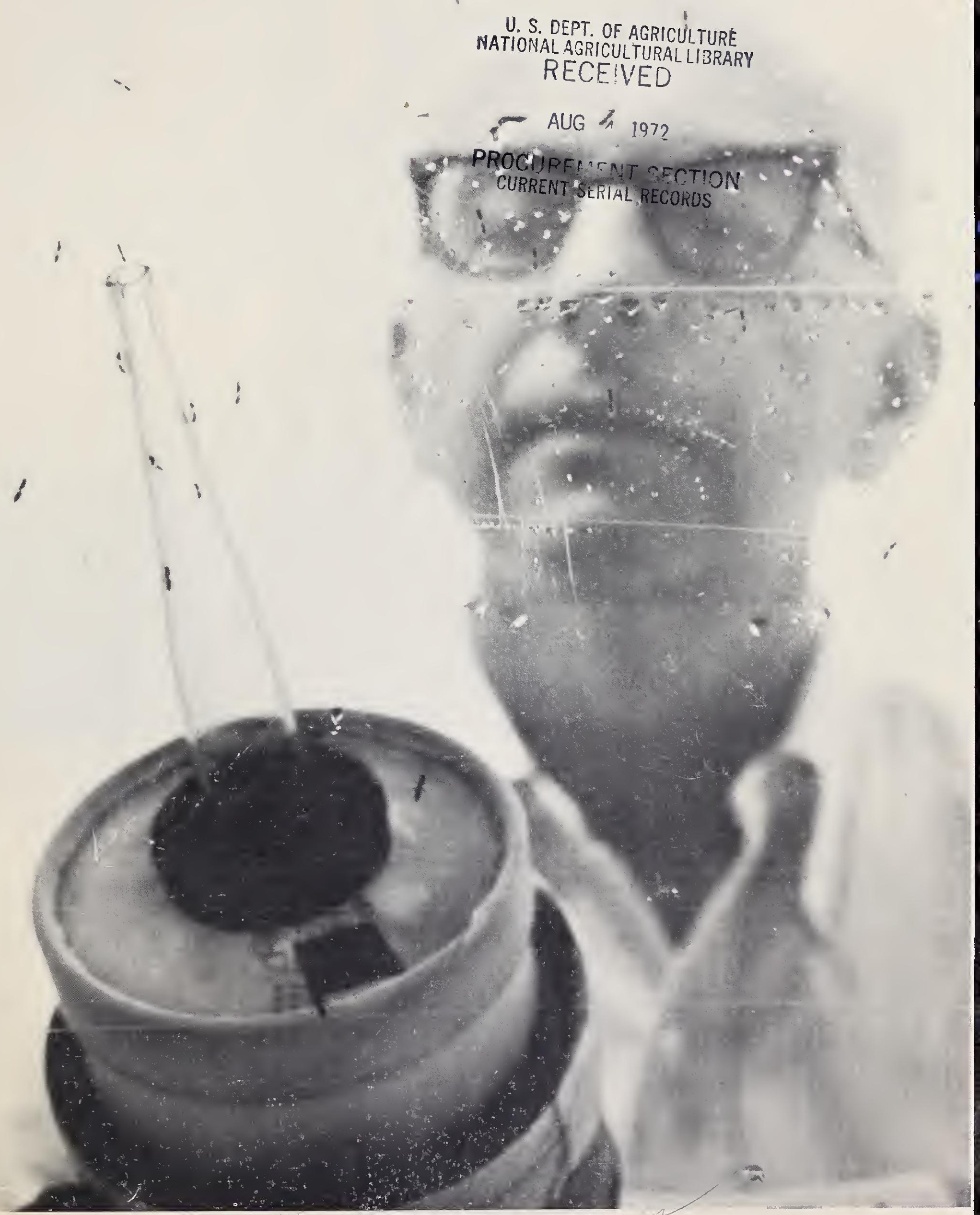




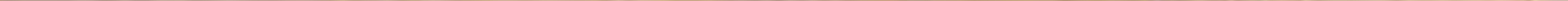



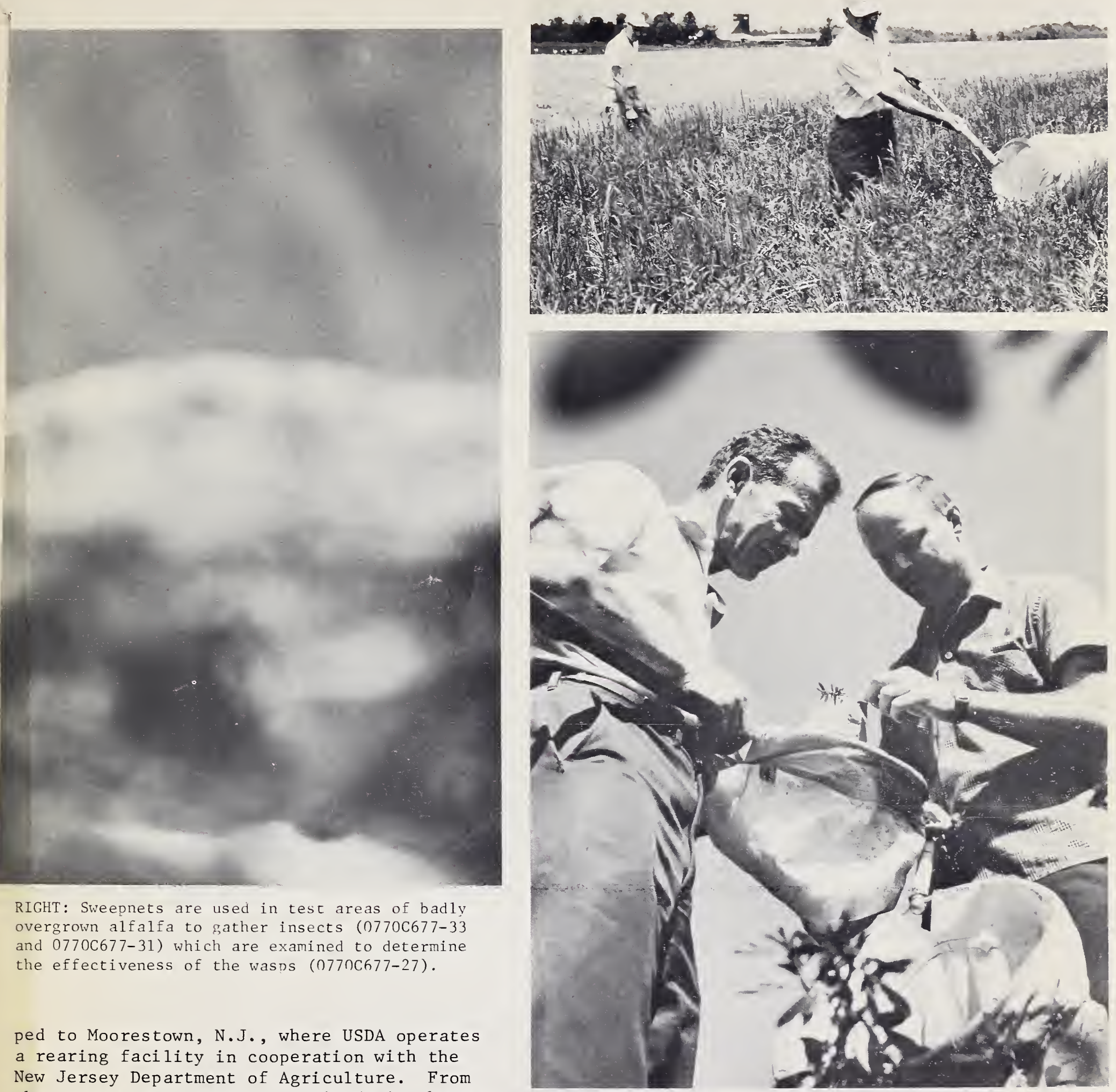

RIGHT: Sweepnets are used in test areas of badly overgrown alfalfa to gather insects (0770C677-33 and 07706677-31) which are examined to determine the effectiveness of the wasps (077nc677-27).

ped to Moorestown, N.J., where USDA operates a rearing facility in cooperation with the New Jersey Department of Agriculture. From there wasps are released in fields in the test area, where frequent surveillance indicates their effectiveness.

Several species of tiny wasps, adapted to varying climates, are being used, but they are all parasites, feeding on the weevil at some stage in its life cycle. Some lay their eggs in weevil egg masses. Upon hatching, wasp larvae eat the weevil eggs.

Prospects are encouraging for eventual control of the weevil in most alfalfa-growing areas of the United States through this biological method.

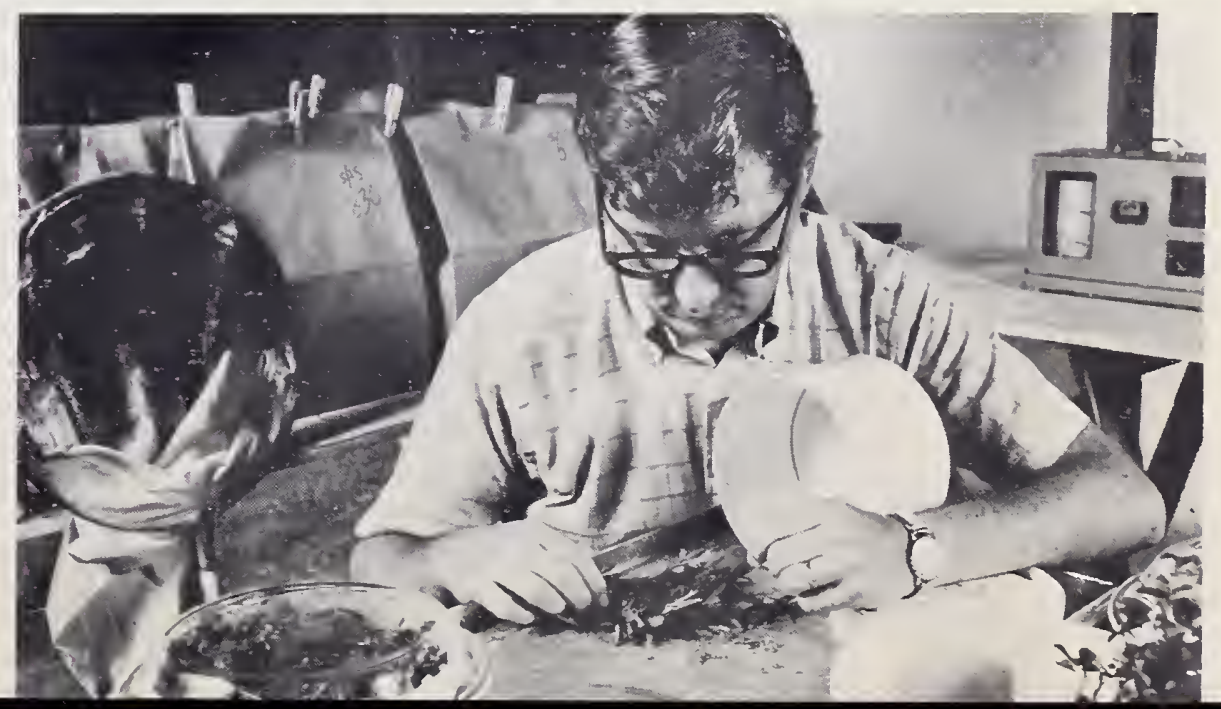




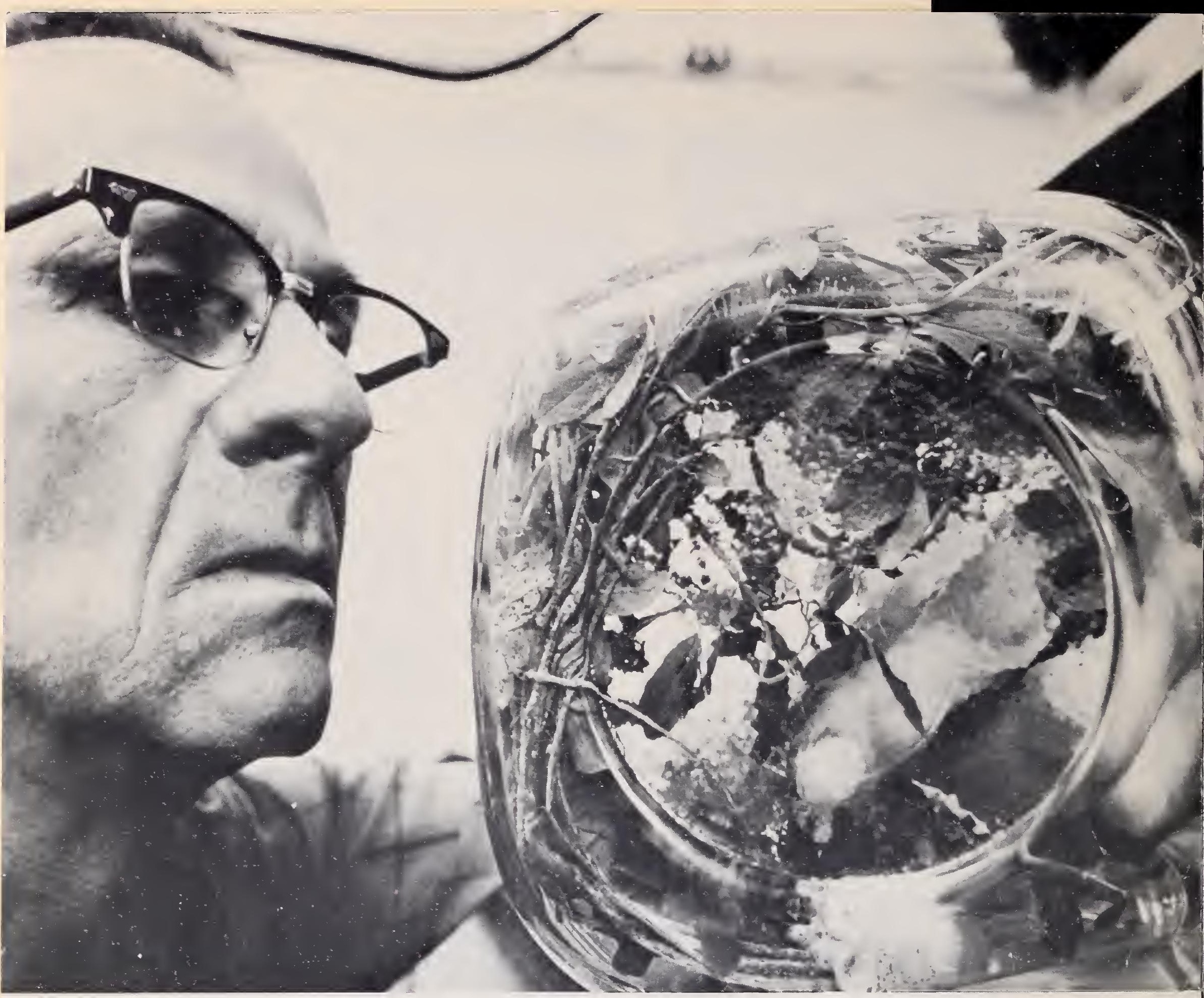

An entomologist checks the progress of weevils and wasps in one of the rearing chambers at the Moorestown facility (0770C677-8).

Magazines and newspapers may obtain $8 \times 10$ prints of these photographs free from the Photography Division, Office of Information. U.S. Department of Agriculture, Washington, D.C. 20250. Specify title and number of this publication.

\section{UNITED STATES DEPARTMENT OF AGRICULTURE OFFICE OF INFORMATION WASHINGTON, D.C. 20250 OFFICIAL BUSINESS}

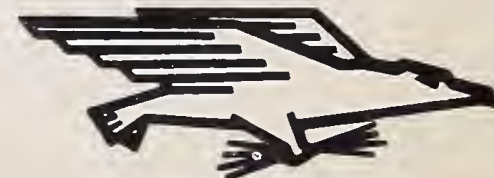

POSTAGE \& FEES PAID

United States Department of Agriculture 